\title{
Inductor Device
}

National Cancer Institute

\section{Source}

National Cancer Institute. Inductor Device. NCI Thesaurus. Code C50003.

A device designed to introduce electromotive force to a circuit, usually a coil surrounding a wire. 